\title{
Porphyrins and Their Metal Complexes in Radical Polymerization of Vinyl Monomers
}

\author{
Regina M. Islamova, ${ }^{\mathrm{a}}{ }^{@}$ Svetlana V. Nazarova $_{1}{ }^{\mathrm{a}}$ and Oscar I. Koifman ${ }^{\mathrm{b}}$ \\ aInstitute of Organic Chemistry of Ufa Scientific Centre of Russian Academy of Sciences, 450054 Ufa, Russia \\ ${ }^{b}$ Ivanovo State University of Chemistry and Technology, 153000 Ivanovo, Russia \\ ${ }^{\circledR}$ Corresponding author E-mail: rmislamova@mail.ru
}

\begin{abstract}
The influence of various porphyrins and their metal complexes which differ in ligand environment and nature of center metal atom on kinetic features of radical polymerization of vinyl monomers, initiated by azo-bis-isobutyronitrile or benzoyl peroxide and on molecular weight characteristics of obtained polymers was studied. Feasible polymerization schemes were proposed.
\end{abstract}

Keywords: Porphyrins, metal complexes, methyl methacrylate, styrene, radical polimerization.

\section{Introduction}

Recently, controlled radical polymerization has become one of the most important methods for producing synthetic vinyl polymers. At the moment several techniques enabling such polymerizations exist, of which ATRP (atom transfer radical polymerization) and RATRP (reverse atom transfer radical polymerization) are the most commonly used ones. ${ }^{[l]}$ The significant advantages of these polymerization techniques include the ability to polymerize polymers with controlled density and chain length, and narrow molecular weight distribution (MWD) in a controlled manner.

A wide range of compounds as alkoxyamines, dithioesters, trithiocarbonates, xanthates and others were proposed as propagation regulators. Metalloorganic compounds of general formula $\mathrm{Mt}^{\mathrm{n} Y \mathrm{~L}}$, where $\mathrm{Mt}$ transition metal ( $\mathrm{Cu}, \mathrm{Fe}, \mathrm{Ru}, \mathrm{Re}, \mathrm{Ni}$ and others); $\mathrm{Y}$ - halogen anion (mainly chlorine or bromine); L - organic ligand (mostly 2,2'-bipyridine, 4,4'-bi-(5-nonyl)-2,2'-pyridine, triphenylphosphine) are of great interests also.
The use of metal complexes of porphyrins in controlled radical polymerization could be very promising. ${ }^{[2-6]}$ Thus, catalytic chain transfer to the monomer and catalytic inhibition were discovered in the polymerization of methacrylates carried out in the presence of cobalt porphyrins. ${ }^{[2-5]}$ It was found by B.B. Wayland and M. Fryd that cobalt complex of tetramesitylporphyrin initiates polymerization of acrylates leading to the formation of homopolymers and block copolymers. ${ }^{[7-9]}$ However, only few metal porphyrins, which are well-soluble in organic media, mainly, cobalt, rhodium, aluminum complexes, allowing the radical polymerization of vinyl monomers under controlled mode, have been studied by now. ${ }^{[7-11]}$

The goal of this work was the study of radical polymerization of vinyl monomers (by the example of methyl methacrylate (MMA) and styrene) initiated by azo-bis-isobutironitrile (AIBN) or benzoyl peroxide (BP) in the presence of various porphyrins and their metal complexes.

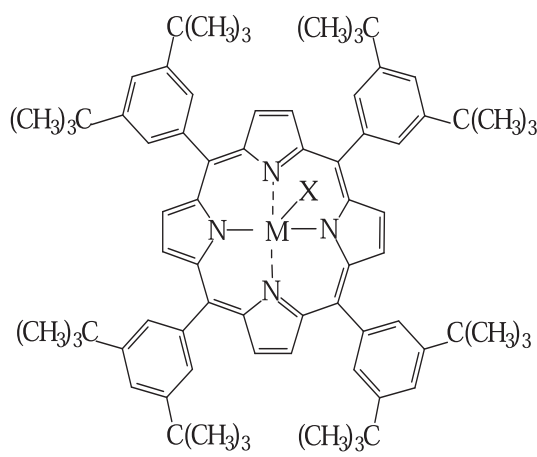

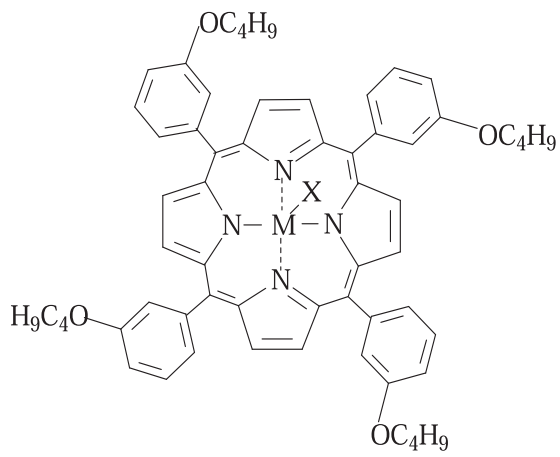

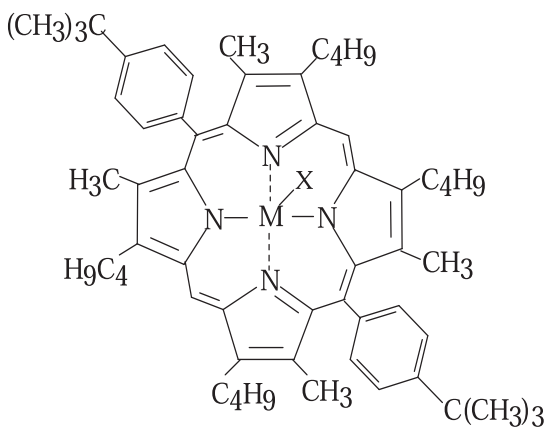

$$
\begin{gathered}
\mathrm{M}-\mathrm{Ti}^{\mathrm{IV}}, \mathrm{X}-\mathrm{O}(\mathbf{1}) ; \\
\mathrm{M}-\mathrm{Zr}^{\mathrm{IV}}, \mathrm{X}-\left(\mathrm{OCOCH}_{3}\right)_{2}(\mathbf{3}) ; \\
\mathrm{M}-\mathrm{Fe}^{\mathrm{IIII}}, \mathrm{X}-\mathrm{Cl}(\mathbf{4}) ; \\
\mathrm{M}-\mathrm{Co}^{\mathrm{III}}, \mathrm{X}-\mathrm{OCOCH}_{3}(\mathbf{7}) ; \\
\mathrm{M}-2 \mathrm{H}(\mathbf{1 0})
\end{gathered}
$$

$\mathrm{M}-\mathrm{Fe}^{\mathrm{III}}, \mathrm{X}-\mathrm{Cl}(\mathbf{6}) ;$
$\mathrm{M}-\mathrm{Co}^{\mathrm{II}}(\mathbf{9})$

$\mathrm{M}-\mathrm{Fe}^{\mathrm{III}}, \mathrm{X}-\mathrm{Cl}(\mathbf{5})$;

$\mathrm{M}-\mathrm{Co}^{\mathrm{III}}, \mathrm{X}-\mathrm{OCOCH}_{3}(\mathbf{8})$; $\mathrm{M}-2 \mathrm{H}$ (11) 


\section{Experimental}

MMA (Fluka) and styrene (Fluka) were distilled two times under reduced pressure: b.p. $=48^{\circ} \mathrm{C}, \mathrm{P}=140 \mathrm{~mm} \mathrm{Hg}$ and b.p. $=52^{\circ} \mathrm{C}$, $\mathrm{P}=27 \mathrm{~mm} \mathrm{Hg}$, correspondingly. AIBN and BP were recrystallized three times from ethanol and dried at room temperature under vacuum to a constant weight. Purity of substances was controlled by ${ }^{13} \mathrm{C}\left\{{ }^{1} \mathrm{H}\right\}$ NMR-spectroscopy. Porphyrins were synthesized and purified as described earlier. ${ }^{[12]}$

Polymerization mixtures were placed into glass ampoules, degassed by three freeze-pump-thaw cycles to residual pressure of $1.3 \mathrm{~Pa}$, sealed and placed in an water (oil) bath at defined temperatures $\left( \pm 0.1{ }^{\circ} \mathrm{C}\right)$. After the predetermined intervals ampoules were cooled and unsealed. The obtained polymers were purified from residual initiator and additive by dissolving into acetone followed by precipitating into 10-15-fold excess methanol three times. The kinetic of bulk polymerization was studied by the dilatometric method. ${ }^{[13]}$

Molecular weight characteristics were determined by gel permeation chromatography. Chromatography was performed on "Waters GPC 2000 System" chromatograph (eluent is tetrahydrofuran; flow rate is $0.5 \mathrm{ml} / \mathrm{min}$ ). Chromatographic columns were calibrated by polystyrene standards $\left(M_{\mathrm{w}} / M_{\mathrm{n}} \leq 1.2\right)$.

${ }^{1} \mathrm{H}$ NMR spectra were recorded in $\mathrm{CDCl}_{3}$ on a "Bruker AM$300^{\prime \prime}$ spectrometer at $25^{\circ} \mathrm{C}$. Tetramethylsilane was used as internal standard. Contents of syndio-, hetero- and isotactic fragments were determined using known method. ${ }^{[14]}$

IR-spectra were recorded in $\mathrm{CCl}_{4}$ on a "Specord M-80" spectrometer in the range from 400 to $4000 \mathrm{~cm}^{-1}$ at $25^{\circ} \mathrm{C}$.

Dynamic thermogravimetric analysis was performed on a "MOM" "Q-1000" derivatograph (heating rate is 5 degree/min, sample mass is $100 \mathrm{mg}$ ). Measurements were taken in air.

Physicochemical characteristics of purified distilled solvents (methanol, acetone, tetrahydrofuran, glycerin, deuterochloroform) satisfy the requirements. ${ }^{[15]}$

\section{Results and Discussion}

\section{Complexes of $\mathrm{Ti}^{I V}$ and $\mathrm{Zr}^{I V}$ with Porphyrins in Radical Polymerization of Vinyl Monomers}

The study on the influence of titanium (1 and 2) and zirconium (3) porphyrins on MMA polymerization in the presence of radical initiators (BP or AIBN) showed that titanium and zirconium porphyrins in combination with BP form initiating systems while in the case of azo-initiator porphyrins do not form such initiating systems. Regardless of radical initiator nature metal complexes of porphyrins can coordinate with monomer (or propagating macroradical) that facilitates more stereospecific addition of monomer to propagating chain. Polymerization process is not influenced by nature of ligand environment in porphyrin macrocycles $\mathbf{1}$ and 2. Except that when porphyrin $\mathbf{2}$ was used as additive an overall polymerization rate was a little higher than that of process carried out in the presence of $\mathbf{1}$ (Figure 1). Zirconium porphyrin 3 influences on kinetic features of MMA polymerization in a less degree than porphyrins $\mathbf{1}$ and $\mathbf{2}$.

Initial rate $\left(W_{0}\right)$ of BP-initiated MMA polymerization in the presence of 1 or 2 at $60^{\circ} \mathrm{C}$ increases by $4-5$ times while when porphyrin 3 is used as additive $W_{0}$ increases by 2-3 times depending on porphyrin concentration. Orders of polymerization reaction on porphyrin 1 at 60,45 and $30^{\circ} \mathrm{C}$ amount to $0.2,0.3$ and 0.1 correspondingly. Order of reaction on $\mathbf{3}$ appears to be negative value since polymerization rate decreases with increase of additive concentration above the optimal one $-0.25 \mathrm{mmol} / \mathrm{l}$. Titanium and zirconium porphyrins differ not only by nature of the complexed transition metal ion but by kind of extra ligand as well. Apparently, acetylacetonate extra ligand in zirconium porphyrin that has stronger electron withdrawing power than oxygen extra ligand in titanium porphyrins draws electrons away from a reaction center and reduces donating power of a porphyrin molecule. Due to this electronic effect decrease of $W_{0}$ with increase of porphyrin $\mathbf{3}$ concentration is observed.

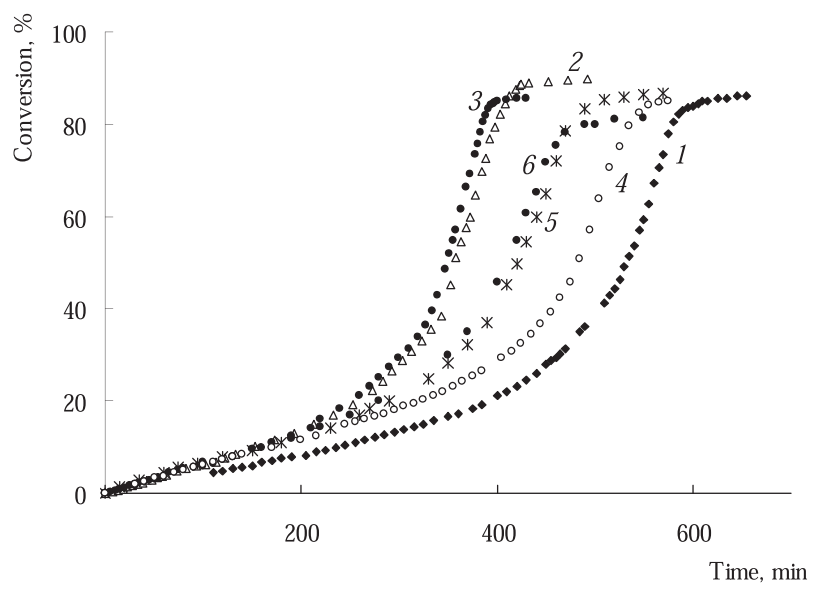

Figure 1. Conversion vs. MMA polymerization time at $60^{\circ} \mathrm{C}$ in the presence of BP (1), BP and porphyrins 1 (2), 2 (3) and 3 (4); $\operatorname{AIBN}(5)$; AIBN and porphyrin $2(6) .[\mathrm{BP}]=[\mathrm{AIBN}]=[1]=[2]=$ $[3]=1.0 \mathrm{mmol} / 1$.

$W_{0}$ increase and overall polymerization rate increase are caused by formation of initiating system "porphyrin (1, 2 or 3) - BP", in other words by interaction of initiator with metal complex of porphyrin results in formation of charge-transfer complex which generates free radicals by dissociation. This assumption is confirmed by values of effective activation energies for systems $\mathbf{1}-\mathrm{BP}$ and $\mathbf{3}-\mathrm{BP}$ that amount to $38 \pm 3$ and $30 \pm 3 \mathrm{~kJ} / \mathrm{mol}$ correspondingly. Calculated values of effective activation energies are about 2-3 times lower than that for MMA polymerization initiated by BP solely $\left(E_{\mathrm{a}}=80 \pm 5 \mathrm{~kJ} / \mathrm{mol}\right)$. Spectral studies indicate formation of initiating systems "metal complex of porphyrin - BP". Thus, the addition of BP solution to porphyrin 1 solution resulted in shift of characteristic absorption band for BP carbonyl group at $1759 \mathrm{~cm}^{-1}$ to the field of higher frequencies for $11 \mathrm{~cm}^{-1}$. In the case of addition of BP solution to porphyrin 3 solution similar bathochromic shift of band for carbonyl group was observed (for $8 \mathrm{~cm}^{-1}$ ). Apparently, "soft" oxidation of metal complex of porphyrin by BP occurs that results in formation of charge-transfer complex which dissociates into $\pi$-cation with delocalized electrons across all the macrocycle, benzoyloxyl radical and benzoyloxyl anion:

$$
\mathrm{M}(\mathrm{X}) \mathrm{P}+\mathrm{Ph}-\mathrm{C}-\mathrm{O}-\mathrm{O}-\mathrm{C}-\mathrm{Ph} \longrightarrow \mathrm{M}(\mathrm{X}) \mathrm{P}^{+}+\mathrm{PhCOO}^{+}+\mathrm{PhCOO}^{+}
$$

And yet there are no changes in IR spectra of mixtures of AIBN solution with titanium or zirconium porphyrins 
solutions that indicates lack of interaction between metal complexes of porphyrins 1-3 and azo-initiator.

Molecular masses of polymethyl methacrylate (PMMA) obtained in the presence of porphyrins 1, 2 or 3 (concentrations amount to 0.25 or $0.5 \mathrm{mmol} / \mathrm{l}$ ) and BP (concentration of BP amounts to $1.0 \mathrm{mmol} / \mathrm{l}$ ) at initial stages of monomer conversion (5-7\%) are about three times lower than ones of control samples. When AIBN is used as initiator molecular masses change insignificantly (Table 1).

Table 1. Molecular weight characteristics of PMMA, synthesized in the presence of BP or AIBN and porphyrins 1,2 and 3 at $60^{\circ} \mathrm{C}$. $[\mathrm{BP}]=[\mathrm{AIBN}]=1.0 \mathrm{mmol} / \mathrm{l}$. Monomer conversion is $5-7 \%$.

\begin{tabular}{ccccc}
\hline $\begin{array}{c}\text { Additive }- \\
\text { initiator }\end{array}$ & $\begin{array}{c}\text { [Additive], } \\
\mathrm{mmol} / 1\end{array}$ & $M_{\mathrm{w}} \cdot 10^{-3}$ & $M_{\mathrm{n}} \cdot 10^{-3}$ & $M_{\mathrm{w}} / M_{\mathrm{n}}$ \\
\hline & 0 & 1600 & 800 & 2.0 \\
$\mathbf{1}-\mathrm{BP}$ & 0.25 & 500 & 290 & 1.8 \\
& 0.5 & 480 & 280 & 1.7 \\
$\mathbf{2}-\mathrm{BP}$ & 1.0 & 470 & 220 & 2.1 \\
& 1.0 & - & - & - \\
$\mathbf{1}-$ AIBN & 0 & 1600 & 840 & 1.9 \\
& 0.1 & 1550 & 820 & 1.9 \\
$\mathbf{2}-$ AIBN & 2.0 & 1500 & 825 & 1.8 \\
& 1.0 & 1410 & 560 & 2.5 \\
$\mathbf{3}-$ BP & 0.25 & 450 & 230 & 2.0 \\
& 0.5 & 500 & 250 & 2.0 \\
& 1.0 & 950 & 470 & 2.0 \\
$\mathbf{3}-$ AIBN & 0.1 & 1590 & 850 & 1.9 \\
& 0.25 & 1600 & 860 & 1.8 \\
& 1.0 & 1500 & 760 & 2.0 \\
\hline
\end{tabular}

The content of syndiotactic fragments in polymer chains obtained in the presence of porphyrins and either of initiators increases by 3-9\%. Decomposition temperature (d.t.) of obtained PMMA increases by about $30-50^{\circ} \mathrm{C}$. Apparently, changes in polydispersity and microstructure can be referred to result of porphyrin influence on chain propagating due to coordination of porphyrin with monomer and macroradical.

Thus, titanium and zirconium porphyrins interact with peroxide initiator and form effective initiating systems results in an increase of MMA polymerization rate and molecular masses decrease. At the same time titanium and zirconium porphyrins coordinate with monomer and improve stereoregularity and thermostability of obtained polymers. When titanium or zirconium porphyrins are used in combination with AIBN, the microstructure and decomposition temperature of PMMA changes while kinetic features remain the same as when polymerization is initiated by AIBN solely. Performances of titanium porphyrins $(\mathbf{1}, \mathbf{2})$ and zirconium porphyrin (3) are similar. The most probable mechanism for MMA polymerization in the presence of titanium and zirconium porphyrins is believed to be complexradical, i.e. some portion of monomer addition reactions occur within metal coordination sphere.

\section{Chlorine-Containing Complexes of Fe ${ }^{I I I}$ with Porphyrins in Radical Polymerization of Methyl Methacrylate and Styrene}

It was shown that the overall rate of the bulk polymerization of MMA initiated by AIBN in the presence of iron porphyrins 4,5 or $\mathbf{6}$ at all studied temperatures (60, $80^{\circ} \mathrm{C}$ ) decreases, gel-effect is suppressed and the conversion of monomer increases linearly on time (Figure 2, Figure 3).

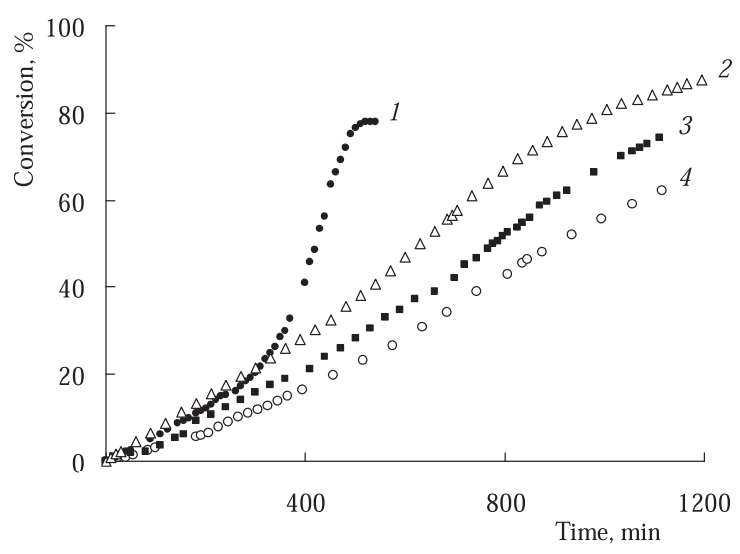

Figure 2. Conversion vs. MMA polymerization time at $60^{\circ} \mathrm{C}$ in the presence of AIBN (1), AIBN and porphyrins 6 (2), 5 (3) and 4 (4). $[\mathrm{AIBN}]=[4]=[5]=[6]=1.0 \mathrm{mmol} / 1$.

The greatest deceleration of polymerization is observed at the use of porphyrin 4 while the use of $\mathbf{6}$ leads to lesser deceleration. An increase in the iron porphyrin 4 concentration from 0.5 to $3.0 \mathrm{mmol} / \mathrm{l}$ facilitates a successive process reduction (Figure 3). Similar concentration dependences were obtained in the cases of the use of $\mathbf{5}$ or $\mathbf{6}$.

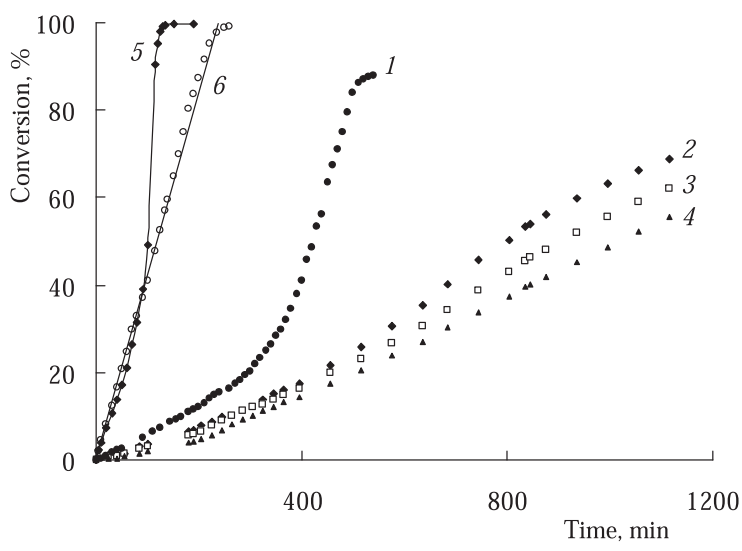

Figure 3. Conversion $v s$. MMA polymerization time at 60 $(1-4)$ and $80^{\circ} \mathrm{C}(5,6)$ in the presence of $\operatorname{AIBN}(1,5)$, AIBN and porphyrin $4(2-4,6)$. [AIBN] $=1.0 \mathrm{mmol} / \mathrm{l} ;[4]=0.5(2), 1.0(3,6)$ and $3.0(4) \mathrm{mmol} / \mathrm{l}$.

Apparently, observed differences in the kinetic patterns of MMA polymerization initiated by AIBN in the presence of iron porphyrins are caused by the features of electron donating and spatial structures of substituents in porphyrin macrocycle. Thus, jointly butyl, methyl and tert-butylphenyl groups in porphyrin $\mathbf{6}$ have more electron-donating ability than tert-butylphenylgroups and butoxyphenyl groups in complexes $\mathbf{4}$ and $\mathbf{5}$. This can facilitate faster decomposition of porphyrin and macroradical adducts and therefore faster proceeding of polymerization process in the presence of porphyrin 6 . But, as a whole, the influences of studied iron porphyrins on MMA radical polymerization are similar. 


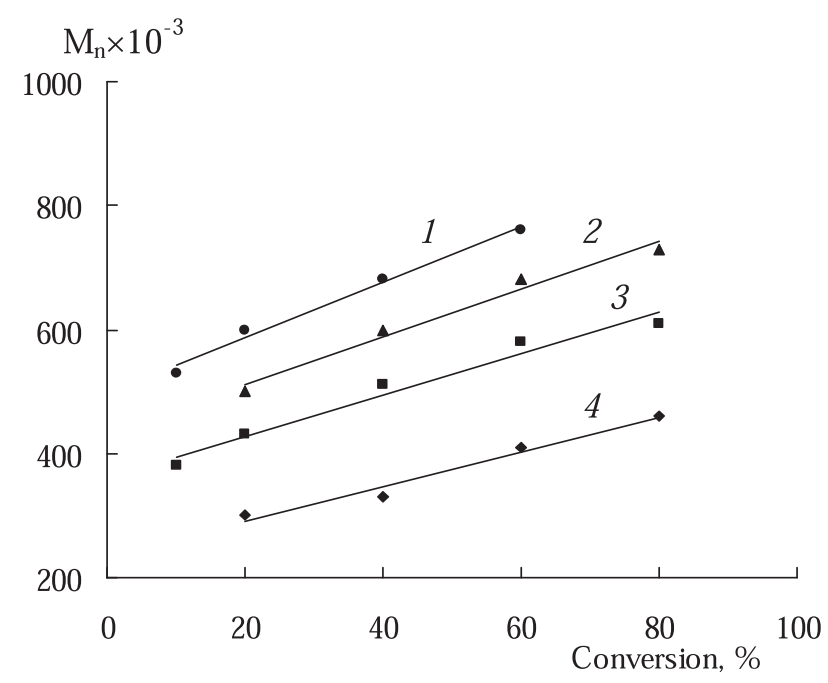

Figure 4. $M_{\mathrm{n}}$ of PMMA obtained in the presence of AIBN and porphyrins $\mathbf{4}(1,4), 5(2)$ and $\mathbf{6}(3) v s$. monomer conversion. $[\mathrm{AIBN}]=[\mathbf{4}]=[\mathbf{5}]=[\mathbf{6}]=1.0 \mathrm{mmol} / \mathrm{l}$. Polymerization temperatures are $60(1-3)$ and $80^{\circ} \mathrm{C}(4)$.

PMMA synthesized in the presence of AIBN and iron porphyrins are transparent and have homogeneous structure without any defects and colors from light-brown to darkbrown according to iron porphyrin concentration. The molecular mass of obtained polymers is about 2-3 times lower than reference samples (which are synthesized solely with azo-initiator without metal complexes of porphyrins). The number-average molecular mass $\left(M_{\mathrm{n}}\right)$ of the polymers obtained in the presence of studied iron porphyrins depends linearly on monomer conversion beginning from $10 \%$ conversion (Figure 4). It should be noted that $M_{\mathrm{n}}$-conversion curves intercepts on an ordinate axis at $250000-500000$. Apparently it is caused by side reactions in polymerization system which will be discussed below. The polydispersity coefficients $\left(M_{\mathrm{w}} / M_{\mathrm{n}}\right)$ of PMMA obtained in the presence of iron porphyrins decrease in comparison to the reference samples and remain almost unchanged during the polymerization process. In the case when porphyrin $\mathbf{4}$ is used $M_{\mathrm{w}} / M_{\mathrm{n}}$ of polymers obtained at $60^{\circ} \mathrm{C}$ amounts to $1.60 \div 1.75$, porphyrin $5-1.50 \div 1.65$ and porphyrin $6-1.40 \div 1.50 . M_{\mathrm{w}} /$ $M_{\mathrm{n}}$ of PMMA synthesized at $80^{\circ} \mathrm{C}$ increases up to $1.70 \div 1.85$. Apparently, number of reactions of regulated addition of monomer to macroradicals decreases with temperature increase. MWD curves for polymers synthesized in the presence of iron porphyrin 4 at 60 and $80^{\circ} \mathrm{C}$ are represented in Figure 5.

They are of the unimodal type and are shifted to the higher molecular masses with conversion. MWD curves of polymers obtained at $60^{\circ} \mathrm{C}$ are narrower than ones of polymers synthesized at $80^{\circ} \mathrm{C}$. Similar curves were obtained in cases of porphyrins 5 and $\mathbf{6}$.

The content of syndiotactic fragments in the chains of PMMA obtained in the presence of iron porphyrins at different conversions at $60^{\circ} \mathrm{C}$ increases by $3-10 \%$, the content of isotactic fragments amounts to $3-5 \%$. D.t. increases by about $10-54^{\circ} \mathrm{C}$ and depends on iron porphyrin. The greatest influence on stereoregularity (the content of syndiotactic fragments increases by $8-10 \%$ ) and on thermostability of polymers (d.t. increases by $52-54^{\circ} \mathrm{C}$ ) is observed in the case of porphyrin $\mathbf{5}$.
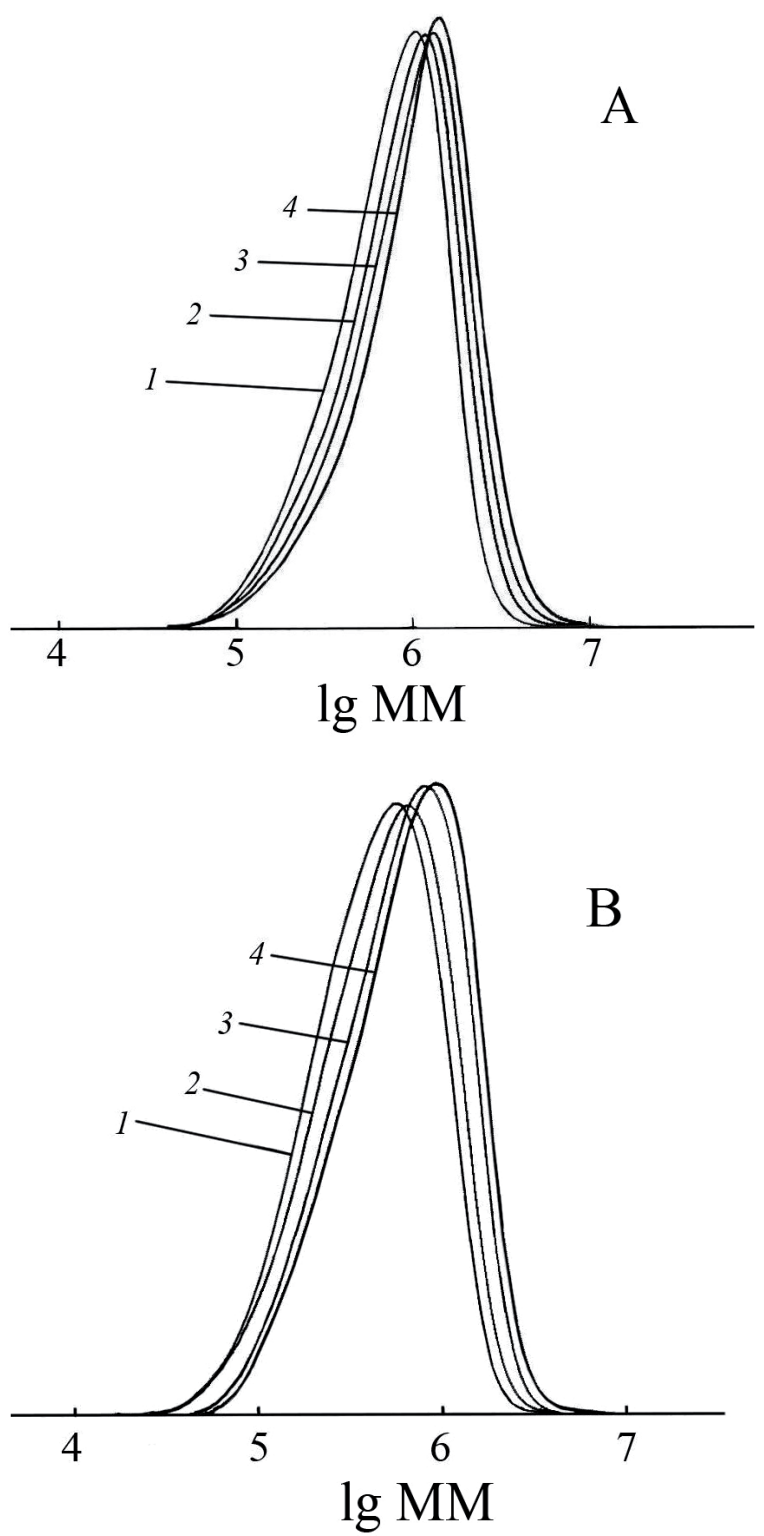

Figure 5. MWD curves of PMMA obtained in the presence of AIBN and porphyrin 4 at $60(\mathrm{~A})$ and $80^{\circ} \mathrm{C}(\mathrm{B})$. [AIBN] $=[4]=1.0$ mmol/1. Monomer conversion, \%: A) 10 (1), 20 (2), 40 (3), 60 (4); B) 20 (1), 40 (2), 60 (3), 80 (4).

In the derivative thermogravimetry curves (DTG) for PMMA obtained in the presence of $\mathbf{5}$ the low-temperature peak at $247^{\circ} \mathrm{C}$ vanishes. Decomposition of PMMA occurs rapidly in narrow temperature interval $\left(270-380^{\circ} \mathrm{C}\right)$ with heat absorption according to results of differential thermal analysis (DTA). Similar DTG and DTA curves were obtained in cases of 4 and 6. Apparently, porphyrins affect low-temperature stage of polymer destruction. The thermostability increase of PMMA synthesized in the presence of iron porphyrins may be caused, on the one hand, by the increase in the content of syndiotactic fragments as a result of more regulated addition of monomer to macroradical and, on the other hand, by the formation of the more stable fragments of metalloporphyrins at polymer chain ends.

The data obtained prove that iron porphyrins 4, 5 and 6 control both stereoregularity of macrochains and molecular 


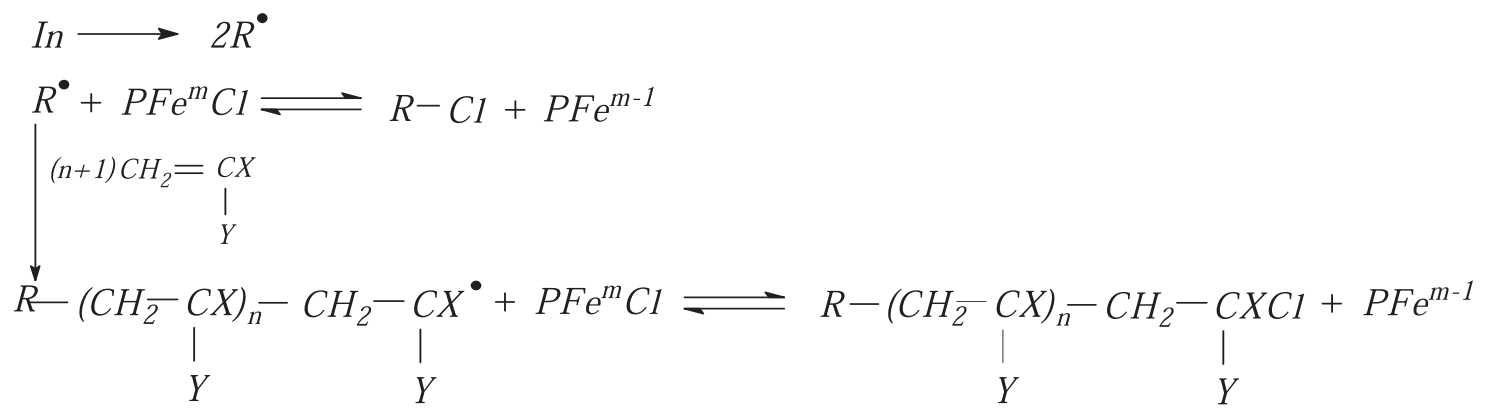

Scheme 1.

mass distribution. The revival of macromolecules can probably occur via the reversible atom transfer mechanism - RATRP ${ }^{[1,16]}$ (Scheme 1).

It should be noted that along with "living" macromolecules there are "dead" macromolecules due to bimolecular termination of macroradicals in simultaneous free-radical polymerization. Therefore $M_{\mathrm{n}}$-conversion curve intercepts on ordinate axis (Figure 4).

The bulk polymerization of styrene initiated by AIBN in the presence of iron porphyrin at $100^{\circ} \mathrm{C}$ occurs practically in the same manner as the process without metal porphyrin. The increase of additive concentration leads to slight decrease in the process rate. Authors ${ }^{[17]}$ mentioned that regulators of "living" radical polymerization not always affect the process rate. It should be noted that successful "living" polymerization requires, as a rule, unique combination of initiating system components, temperatures, etc. for particular monomer.

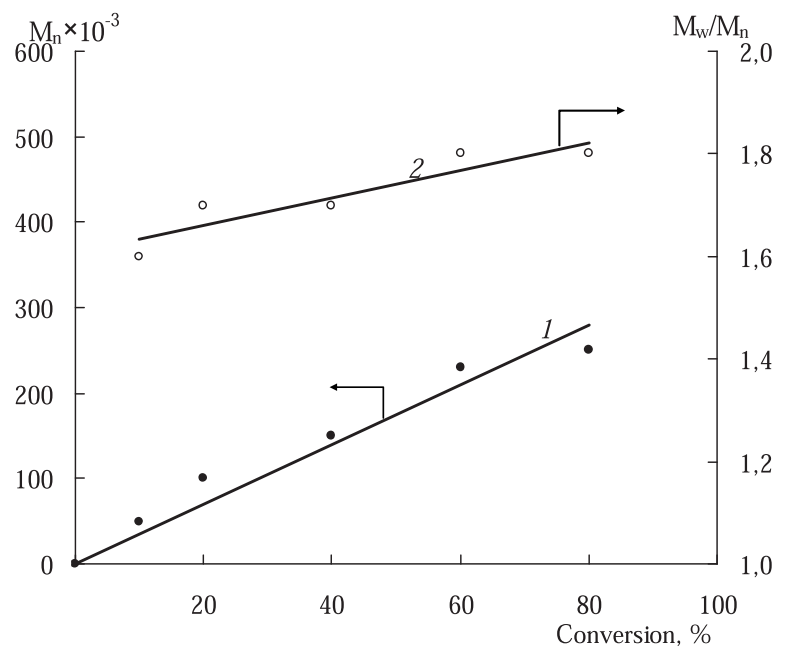

Figure 6. $M_{\mathrm{n}}(1)$ and $M_{\mathrm{w}} / M_{\mathrm{n}}(2)$ of polystyrene obtained in the presence of AIBN and porphyrin 6 at $100^{\circ} \mathrm{C} v s$. monomer conversion. $[\mathrm{AIBN}]=[\mathbf{6}]=1.0 \mathrm{mmol} / \mathrm{l}$.

Polystyrene obtained in the presence of iron porphyrins has similar features (homogeneity, color, molecular characteristics) as PMMA synthesized on basis of iron porphyrins. Thus, the molecular mass of polystyrene obtained in the presence of iron porphyrin 6 is about 2-3 times lower than reference samples, which are synthesized solely with AIBN. $M_{\mathrm{n}}$ depends linearly on monomer conversion, $M_{\mathrm{w}} / M_{\mathrm{n}}$ amounts to $1.65 \div 1.80$ and remain almost unchanged during the polymerization process (Figure 6). MWD curves are of the unimodal type and are shifted to the higher molecular masses with conversion. Similar dependences were obtained in cases of porphyrins $\mathbf{4}$ and $\mathbf{5}$. It is known that acryl and methacryl monomers show higher activity than styrene in polymerization processes. Nevertheless general trend of MMA or styrene polymerization initiated by AIBN in the presence of iron porphyrins is the same and the overall mechanism is RATRP.

If $\mathrm{BP}$ is used as an initiator in the polymerization of MMA, the addition of iron porphyrins leads to essential decrease in the process rate (Figure 7). Thus, yield of PMMA does not exceed $20 \%$ for more than 20 hours at equimolar concentration of components (concentrations of initiator and additive amounts to $1.0 \mathrm{mmol} / \mathrm{l})$ at $60^{\circ} \mathrm{C}$. When the concentration of iron porphyrin 6 is increased from 0.5 to $3.0 \mathrm{mmol} / \mathrm{l}$ (concentration of BP amounts to $1.0 \mathrm{mmol} / \mathrm{l}$ ) the ultimate yield of polymer come to $15 \%$ for 25 hours, i.e. polymerization decelerates dramatically right after the decomposition of BP. Similar dependences were obtained in the cases of use of $\mathbf{4}$ and $\mathbf{5}$. Even if the temperature of process is increased to $80^{\circ} \mathrm{C}$ and polymerization system is heated for several days the yield of PMMA does not exceed $20 \%$.

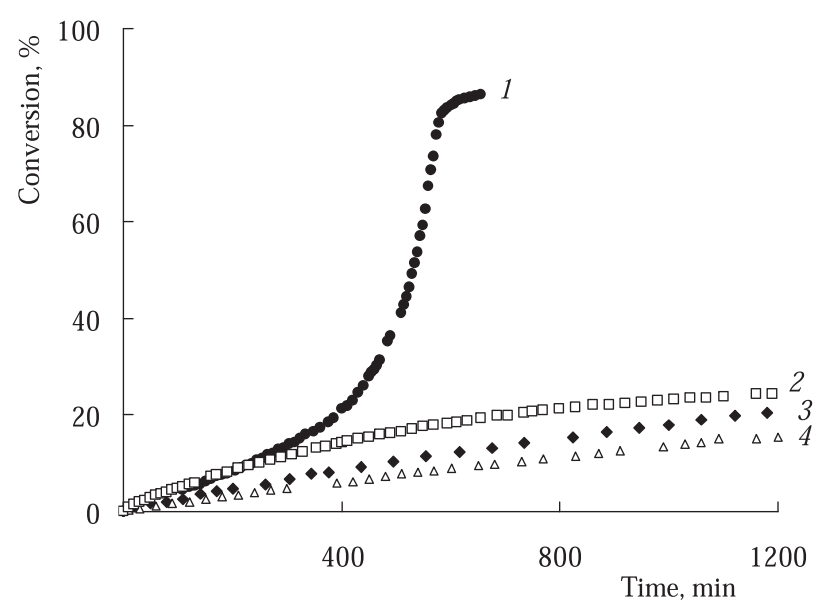

Figure 7. Conversion vs. MMA polymerization time at $60^{\circ} \mathrm{C}$ in the presence of BP (1), BP and porphyrins 6 (2), 5 (3) and 4 (4). $[\mathrm{BP}]=[\mathbf{4}]=[\mathbf{5}]=[\mathbf{6}]=1.0 \mathrm{mmol} / \mathrm{l}$.

As was mentioned earlier ${ }^{[1]}$ polymerization initiated by peroxides behaves quite differently from "living" polymerization due to complexation of metalloorganic compounds with initiator resulting in formation of inactive in polymerization process products. The results of polymerization investigation also could be a proof of complexation of additive with initiator. However efforts on 
complexation study by spectral methods were unsuccessful as paramagnetic complexes of porphyrins $4-6$ caused broadening and tailing of NMR-spectra. UV-spectra didn't show signs of interaction of additive with BP either. Still by quantum chemical calculations ${ }^{[18]}$ it was shown that iron porphyrin 4 readily couples with benzoyloxyl radicals formed from decomposition of BP. Calorific effect of reaction is $-117.4 \mathrm{~kJ} / \mathrm{mol}$. Thus, porphyrin 4 dramatically decelerates MMA polymerization "trapping" free radicals.

The nature of monomer, which plays an important role, should be taken into consideration as well. Thus, the rate of the BP-initiated styrene polymerization in the presence of iron porphyrins decreases also, but not as dramatically as in the case of MMA polymerization. $M_{n}$ of obtained polystyrene depends linearly on monomer conversion, $M_{\mathrm{w}} / M_{\mathrm{n}}$ decreases (Figure 8), i.e. the features of "living" polymerization are observed. Apparently, complexation of iron porphyrin with BP is affected by medium polarity. In polar MMA coordination of iron porphyrin with $\mathrm{BP}$ (or $\mathrm{PhCOO}^{*}$ ) occurs easier than in styrene. Apparently, the different ways of complexation of $\mathrm{BP}$ with iron porphyrins and BP with titanium or zirconium porphyrins which have similar structures are specified by kind of extra ligand in these macro complexes which has effect on coordination ability.

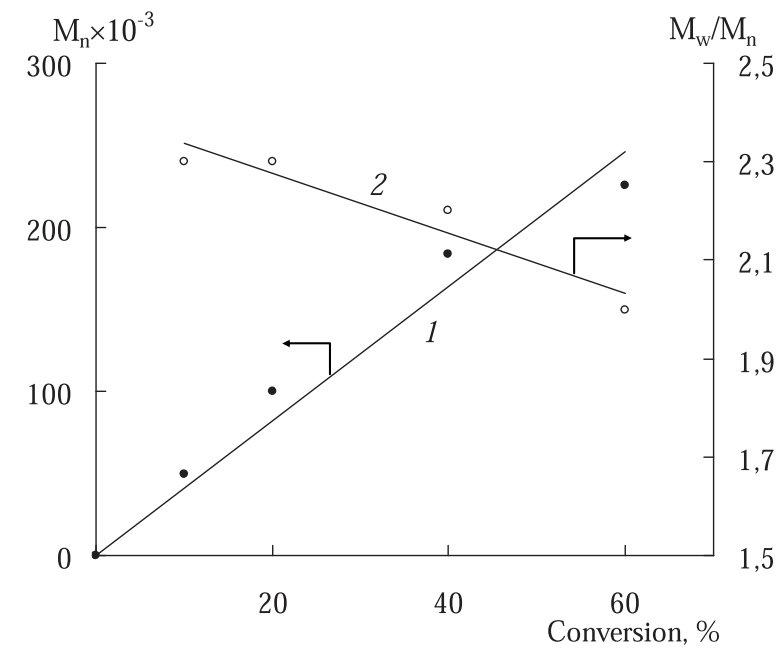

Figure 8. $M_{\mathrm{n}}(1)$ and $M_{\mathrm{w}} / M_{\mathrm{n}}$ (2) of polystyrene obtained in the presence of $\mathrm{BP}$ and porphyrin 6 at $100^{\circ} \mathrm{C} v s$. monomer conversion. $[\mathrm{BP}]=[\mathbf{6}]=1.0 \mathrm{mmol} / \mathrm{l}$.

Thus, on the basis of experimental data it can be concluded that in MMA and styrene polymerization initiated by azo-initiator in the presence of iron porphyrins of different structure, features of controlled radical polymerization via RATRP are observed. Along with the regulation of MWD the additives have effect on stereo regularity of synthesized polymers. In general the influences of studied iron porphyrins on polymerization processes are similar. Specific feature is inhibition of BP-initiated polymerization of MMA in the presence of iron porphyrins, while the polymerization of styrene occurs to high monomer conversion upon the same condition. Molecular weight characteristics of obtained polystyrene correspond to ones that characterize polymers produced upon "living" polymerization.

\section{Cobalt Porphyrins in Radical Polymerization} of Vinyl Monomers

Radical polymerization of MMA initiated by AIBN in the presence of cobalt porphyrins 7,8 or 9 at $60^{\circ} \mathrm{C}$ was studied.

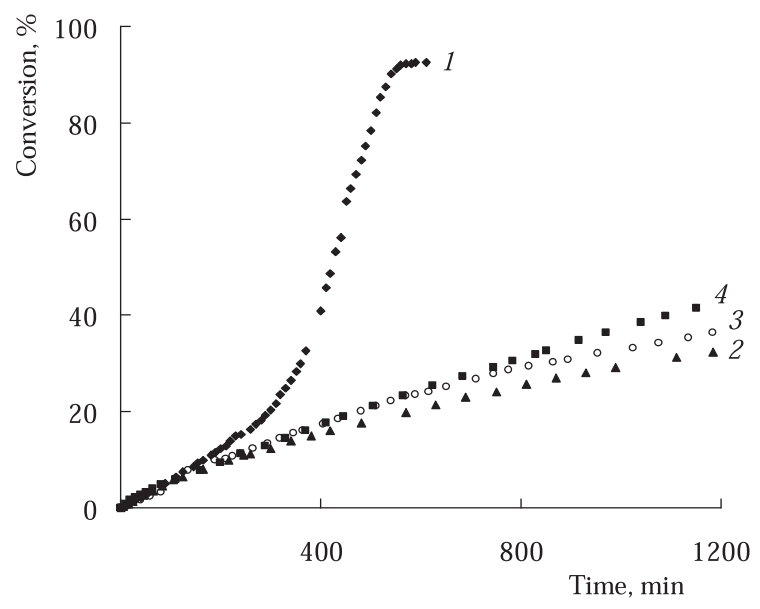

Figure 9. Conversion vs. MMA polymerization time at $60^{\circ} \mathrm{C}$ in the presence of AIBN (1), AIBN and porphyrins 7 (2), 8 (3) and 9 (4). $[\mathrm{AIBN}]=[7]=[8]=[9]=1.0 \mathrm{mmol} / \mathrm{l}$.

According to the influence on the overall polymerization rate cobalt porphyrins could be placed in following order: $\mathbf{9}>\mathbf{8}>\mathbf{7}$ (Figure 9). In the case of iron porphyrins similar order is observed: $\mathbf{6}>\mathbf{5}>\mathbf{4}$ (Figure 2). Cobalt porphyrins decelerate polymerization greater than iron porphyrins. Thus, at the addition of cobalt porphyrins the ultimate yield of PMMA did not exceed $40 \%$ for 20 hours (Figure 9). When the concentration of cobalt porphyrin is increased from 0.25 to $1.0 \mathrm{mmol} / 1$ the polymerization rate decreases. In the cases of cobalt porphyrins $\mathbf{7}$ and $\mathbf{8}$ similar dependences of the process rate on additive concentrations were observed.

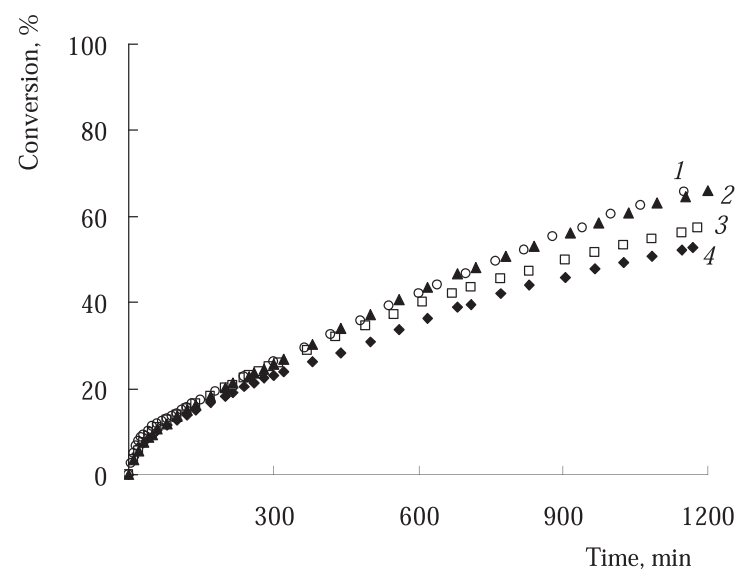

Figure 10. Conversion $v s$. styrene polymerization time at $100^{\circ} \mathrm{C}$ in the presence of $\operatorname{AIBN}(1), \mathrm{AIBN}$ and porphyrins 7 (2), 8 (3) and 9 (4). $[\mathrm{AIBN}]=[7]=[\mathbf{8}]=[\mathbf{9}]=1.0 \mathrm{mmol} / 1$.

Studied cobalt porphyrins as well as iron porphyrins practically do not have effect on the kinetic features of styrene polymerization (Figure 10). The increase of additive concentration leads to decrease in overall process rate. 


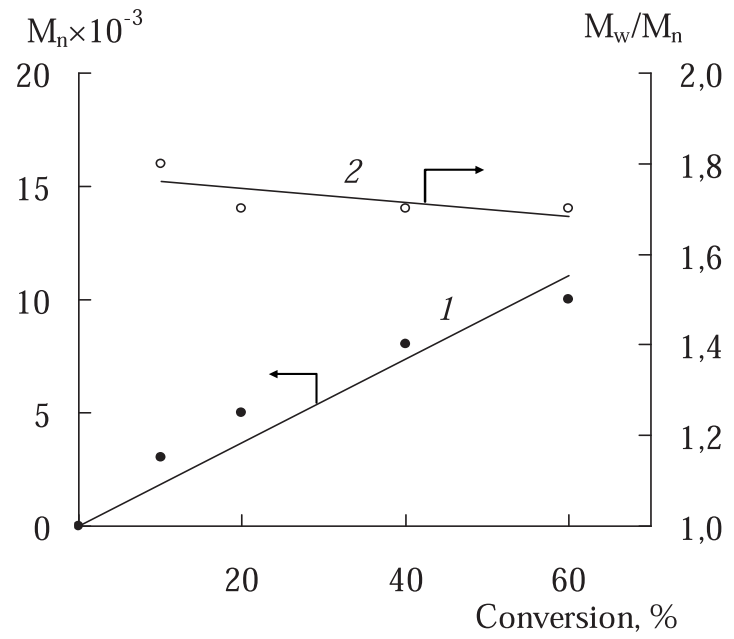

Figure 11. $M_{\mathrm{n}}(1)$ and $M_{\mathrm{w}} / M_{\mathrm{n}}(2)$ of polystyrene obtained in the presence of AIBN and porphyrin 9 at $100^{\circ} \mathrm{C} v s$. monomer conversion. [9] $=0.5 \mathrm{mmol} / \mathrm{l} ;$ [AIBN] $=1.0 \mathrm{mmol} / \mathrm{l}$.

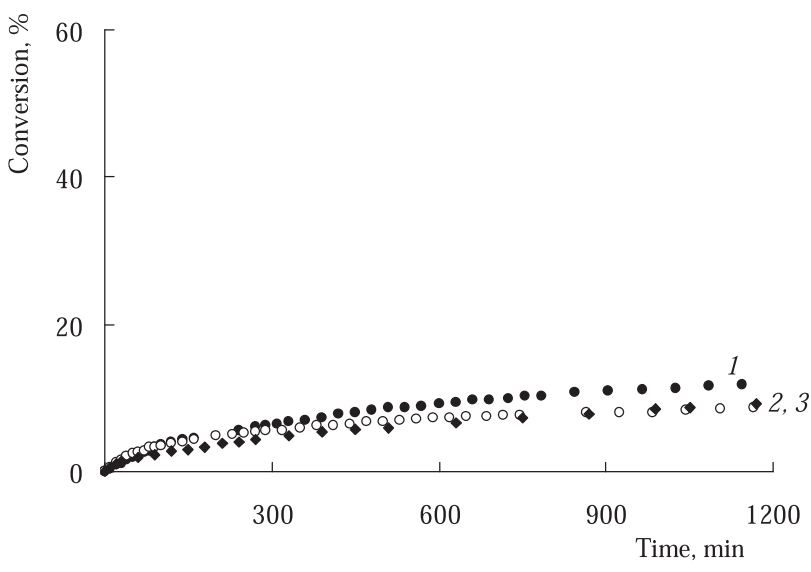

Figure 12. Conversion vs. MMA polymerization time at $60^{\circ} \mathrm{C}$ in the presence of $\mathrm{BP}$ and porphyrins 7 (3), 8 (1) and 9 (2). [BP] = $[7]=[8]=[9]=1.0 \mathrm{mmol} / 1$.

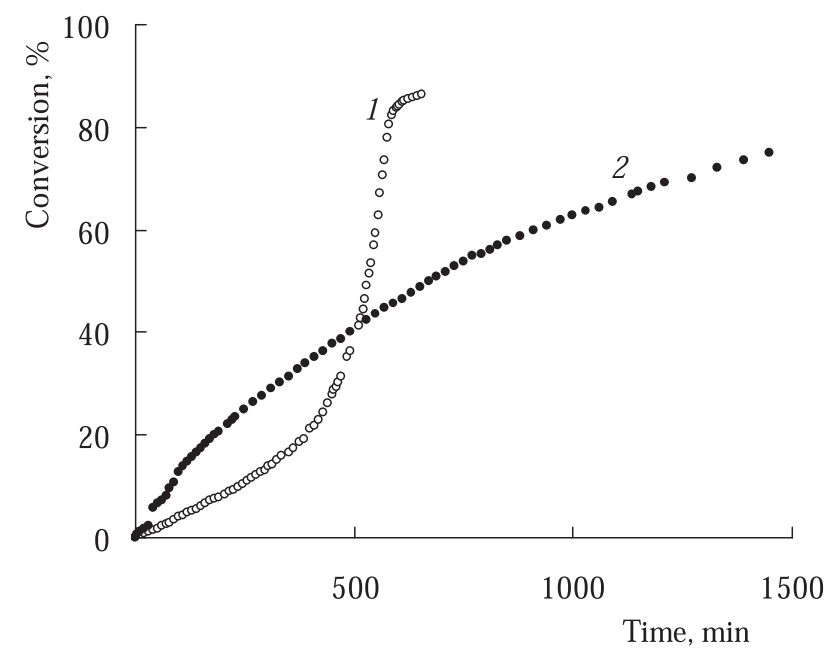

Figure 13. Conversion $v s$. MMA polymerization time at $60^{\circ} \mathrm{C}$ in the presence of $\mathrm{BP}$ and porphyrins 7. $[\mathrm{BP}]=1.0 \mathrm{mmol} / \mathrm{l} ;[7]=0$ (1), $0.5 \mathrm{mmol} / \mathrm{l}(2)$.
$M_{\mathrm{n}}$ of polystyrene synthesized in the presence of AIBN and 9 depends linearly on monomer conversion, but values of $M_{\mathrm{w}} / M_{\mathrm{n}}$ exceed ones that characterize polymers produced upon "living" polymerization and amounts to $1.80-1.70$ (Figure 11). MWD curves of the unimodal type and are shifted to the higher molecular masses with conversion.

Table 2. Kinetic features of MMA polymerization and PMMA molecular weight characteristics obtained in the presence of BP and porphyrin 7 at different temperatures. $[\mathrm{BP}]=1.0 \mathrm{mmol} / \mathrm{l}$. Monomer conversion is 5-7\%.

\begin{tabular}{cccccc}
\hline $\mathrm{T},{ }^{\circ} \mathrm{C}$ & $\begin{array}{c}\mathrm{C}(7), \\
\mathrm{mmol} / 1\end{array}$ & $\begin{array}{c}W_{0}, \\
\mathrm{mmol} / 1 \cdot \mathrm{min}\end{array}$ & $M_{\mathrm{w}} \cdot 10^{-3}$ & $M_{\mathrm{n}} \cdot 10^{-3}$ & $M_{\mathrm{w}} / M_{\mathrm{n}}$ \\
\hline \multirow{3}{*}{60} & 0 & 4.0 & 1960 & 980 & 2.0 \\
& 0.25 & 8.0 & 1200 & 500 & 2.3 \\
& 0.50 & 8.3 & 100 & 35 & 3.0 \\
& 1.00 & 9.2 & \multicolumn{3}{c}{ low molecular products } \\
\hline \multirow{3}{*}{45} & 0 & 1.1 & 2500 & 1150 & 2.0 \\
& 0.25 & 1.9 & 1360 & 680 & 2.0 \\
& 1.00 & 3.1 & low molecular products \\
\hline \multirow{3}{*}{30} & 0 & 0.3 & 3300 & 1760 & 2.0 \\
& 0.25 & 0.6 & 1800 & 820 & 2.2 \\
& 0.50 & 0.9 & 430 & 120 & 3.6 \\
\hline
\end{tabular}

If benzoyl peroxide is used as an initiator the addition of studied cobalt porphyrins (the concentration of additive amounts to $1.0 \mathrm{mmol} / \mathrm{l}$ ) leads to stoppage of MMA polymerization (Figure 12). Thus, under existing conditions yield of PMMA does not exceed $10 \%$ for more than 20 hours. However, BP-initiated polymerization of MMA in the presence of $0.5 \mathrm{mmol} / 1$ of cobalt porphyrin 7 proceeds up to high conversions of monomer (Figure 13). At initial stages acceleration of the process which is followed by decrease in overall polymerization rate starting from 30$40 \%$ of monomer conversion is observed. Kinetic features of polymerization initial stages in the presence of cobalt porphyrin 7 were investigated in detail.

$W_{0}$ of BP-initiated bulk polymerization of MMA in the presence of cobalt porphyrin 7 increases and molecular masses of produced PMMA decrease dramatically when additive concentration is increased from 0.25 to $1.0 \mathrm{mmol} / \mathrm{l}$ at all studied temperatures (Table 2). At concentration of cobalt porphyrin of $1.0 \mathrm{mmol} / \mathrm{l}$ products with low molecular weights were obtained. All efforts to separate out these products from solution were unsuccessful. It is shown in ${ }^{[2-5]}$ by Smirnov et al. that decrease of molecular masses is due to cobalt porphyrin catalyzed chain transfer reactions on monomer.

$W_{0}$ increases and molecular masses of polymers decrease with temperature increase naturally (Table 2). Calculated value of effective activation energy amounts to $53 \pm 5 \mathrm{~kJ} / \mathrm{mol}$ which is lower than that of polymerization process initiated by BP solely $(80 \pm 5 \mathrm{~kJ} / \mathrm{mol})$. Apparently, considering that propagating and termination activation energies are negligible, ${ }^{[13]}$ activation energy of initiation decreases.

It was mentioned in ${ }^{[5]}$ that peroxides can cause "poisoning" of cobalt porphyrins as chain transfer 
catalysts. Studies were carried out using tetramethylether of hematoporphyrin mainly. In the case of porphyrin 7 "poisoning" of catalyst was not observed, which is evidenced by the decrease in the auto acceleration, the decrease of molecular masses of obtained PMMA and the increase of initial polymerization rate.

Table 3. Molecular weight characteristics of PMMA synthesized in the presence of $\mathrm{BP}$ and porphyrin 7 at $60^{\circ} \mathrm{C} v$ s. conversion. [BP] $=1.0 \mathrm{mmol} / 1$.

\begin{tabular}{ccccc}
\hline $\begin{array}{c}\mathrm{C}(7), \\
\mathrm{mmol} / 1\end{array}$ & Conversion, \% & $M_{\mathrm{w}} \cdot 10^{-3}$ & $M_{\mathrm{n}} \cdot 10^{-3}$ & $M_{\mathrm{w}} / M_{\mathrm{n}}$ \\
\hline \multirow{4}{*}{0.25} & 3 & 1200 & 500 & 2.4 \\
& 8 & 1450 & 620 & 2.3 \\
& 10 & 1600 & 720 & 2.2 \\
& 20 & 2200 & 870 & 2.5 \\
& 40 & 2400 & 880 & 2.7 \\
0.50 & 60 & 2600 & 900 & 2.9 \\
\hline \multirow{3}{*}{} & 3 & 100 & 35 & 2.9 \\
& 10 & 115 & 40 & 2.9 \\
& 20 & 120 & 40 & 3.0 \\
& 60 & 140 & 60 & 2.3 \\
& & 165 & 75 & 2.2 \\
\hline
\end{tabular}

$M_{\mathrm{n}}$ value of PMMA synthesized in the presence of $\mathrm{BP}$ and cobalt porphyrin 7 increases linearly on monomer conversion at all studied porphyrin concentration, $M_{\mathrm{w}} / M_{\mathrm{n}}$ amount to 2.0-3.0 (Table 3). MWD curves for polymers obtained at the concentration of cobalt porphyrin 7 of 0.25 $\mathrm{mmol} / \mathrm{l}$ are of the unimodal type and become broader at high conversions (Figure 14). MWD curves for PMMA synthesized at $0.5 \mathrm{mmol} / 1$ of cobalt porphyrin 7 are of the bimodal type and become narrower in the course of polymerization (Figure 15). Apparently, the influence of cobalt porphyrin on molecular mass characteristics of obtained polymers increases at concentration of cobalt porphyrin of $0.5 \mathrm{mmol} / 1$ and higher.

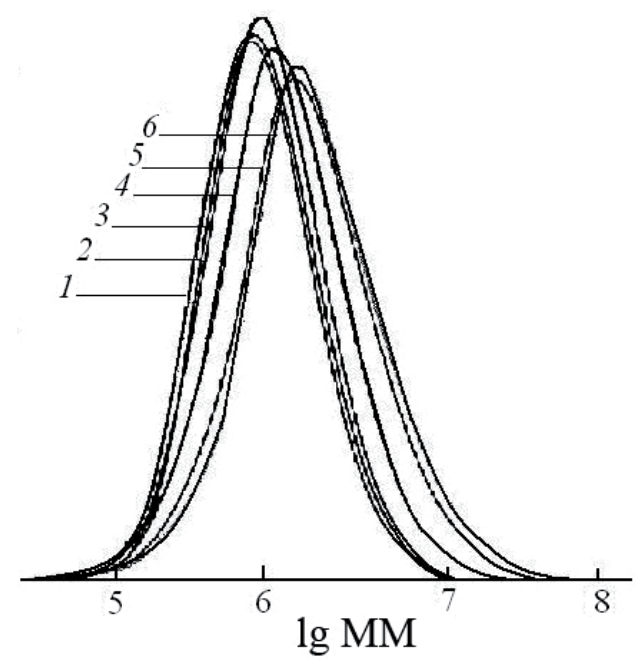

Figure 14. MWD curves of PMMA obtained in the presence of $\mathrm{BP}$ and porphyrin 7 at $60^{\circ} \mathrm{C}$. [BP] $=1.0 \mathrm{mmol} / 1$;

[7] $=0.25 \mathrm{mmol} / \mathrm{l}$. Monomer conversion, \%: 3 (1), 8 (2), 10 (3), 20 (4), 40 (5), 60 (6).

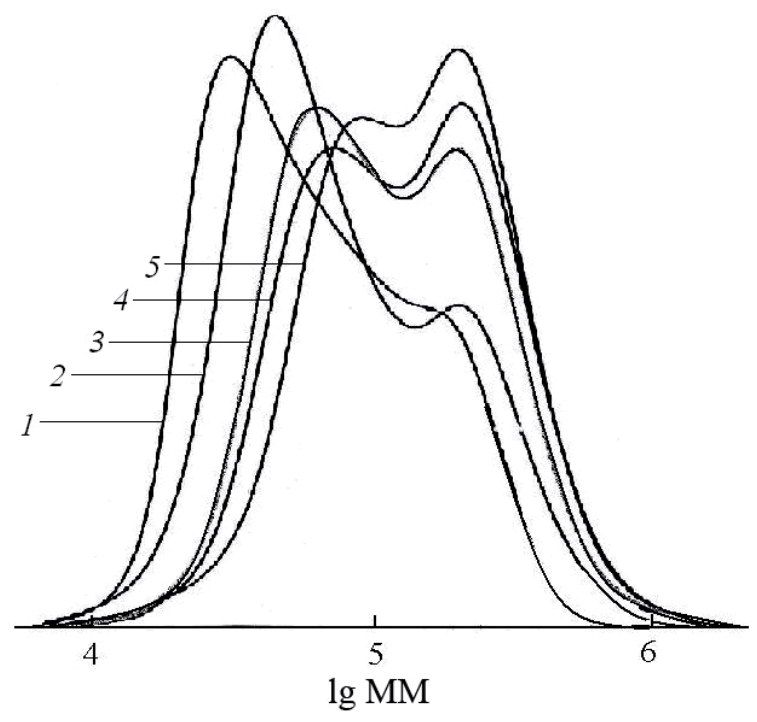

Figure 15. MWD curves of PMMA obtained in the presence of $\mathrm{BP}$ and porphyrin 7 at $60^{\circ} \mathrm{C}$. [BP] $=1.0 \mathrm{mmol} / \mathrm{l} ;[7]=0.5 \mathrm{mmol} / 1$. Monomer conversion, \%: 3 (1), 8 (2), 10 (3), 20 (4), 60 (5).

The content of syndiotactic fragments in polymers obtained in the presence of cobalt porphyrin 7 increases by $\sim 8 \%$. Similar results were obtained for polymers synthesized in the presence of iron porphyrins. Earlier kinetic nonuniformity distribution of chain growth sites were calculated by mathematic analysis of MWD curves using Tikhonov's regularization method for ion-coordinating polymerization. It was shown that macrochains could be formed by two kinds of active sites - free radicals or radicals that have coordination bond with molecule of cobalt porphyrin. ${ }^{[19]}$ It is the formation of last particles that causes bimodal MWD and an increase of syndiotactic fragments in polymer chains providing energy-optimal conditions for addition of monomer to propagating macroradical. Apparently, the decrease of effective activation energy of polymerization process is result of cobalt porphyrin catalytic effect on BP decomposition.

Thus, polymerization carried out in the presence of cobalt porphyrins tends to complex-radical process ${ }^{[20]}$ complicated by chain transfer reaction on monomer. Furthermore, conventional free radical polymerization contributing to overall polymerization process should be taken into consideration.

\section{Conclusions}

On the basis of experimental data it can be concluded that studied metal complexes of porphyrins are promising modifying additives for controlled radical polymerization of vinyl monomers that have an effect on all stages of polymerization process - initiation, propagating and termination, and on molecular weight characteristics of obtained polymers. Performances of metal complexes of porphyrins during polymerization process have relationships to their structure.

Acknowledgements. This work was supported by the Russian Foundation of Basic Research (grants No. 10-0300027-a and 10-03-00967-a). 


\section{References}

1. Matyjaszewski K., Xia J. Chem. Rev. 2001, 101, 2921-2990.

2. Smirnov B.R. Vysokomol. Soedin. 1990, 32, 583-589 (in Russ.).

3. Smirnov B.R., Plotnikov V.D., Ozerkovskii B.V., Roshchupkin V.P., Enikolopyan N.S. Vysokomol. Soedin. 1981, 23, 25882595.

4. Smirnov B.R., Belgovskii I.M., Ponomarev G.V., Marchenko A.P., Enikolopyan N.S. Dokl. Akad. Nauk SSSR 1980, 254, 127-130.

5. Porfiriny: Struktura, Svoistva, Sintez [Porphyrins: Structure, Properties, Synthesis] (Enikolopyan N.S., Ed.) Moskva: Nauka, 1985. 333 p. (in Russ.).

6. Koifman O.I., Ageeva T.A. Porfirinpolimery [Porphyrinpolymers]. Moskva: Izd. Fiz.-mat. Liter., 2006. 195 p. (in Russ.).

7. Wayland B.B., Poszmik G., Mukerjee S.L. J. Amer. Chem. Soc. 1994, 116, 7943-7944.

8. Lu Zh., Fryd M., Wayland B.B. Macromolecules 2004, 37, 2686-2687.

9. Wayland B.B., Poszmik G., Fryd M. Organometallics 1992, 11, 3534-3542.

10. Kuroki M., Aida T., Inoue S. J. Amer. Chem. Soc. 1987, 109, 4737-4738.
11. Hosokawa Y., Kuroki M., Aida T., Inoue S. Macromolecules 1991, 24, 824-829.

12. Smith K.M. Porphyrins and Metalloporphyrins. AmsterdamLondon-New York: Elsevier, 1975. 910 p.

13. Gladyshev G.P. Polimerizatsiya Vinilovykh Monomerov [Polymerization of Vinyl Monomers]. Alma-Ata: Nauka, 1964. 322 p. (in Russ.).

14. Ferguson R.C., Ovenall D.W. Polym. Prepr. (Am. Chem. Soc., Div. Polym. Chem.) 1985, 26, 182-183.

15. Gordon A., Ford R. The Chemist's Companion. A Wiley Intersciens Publication, New York London - Sydney -Toronto, 1972.

16. Matyjaszewski K., Davis T.P. Handbook of Radical Polymerization. New-York: Wiley-Interscience, 2002. 920 p.

17. Barner-Kowollik C., Quinn J.F., Nguyen T.L.U., Heuts J.P.A., Davis T.P. Macromolecules 2001, 34, 7849-7857.

18. Friesen A.K. Macroheterocycles 2009, 2, 243-245.

19. Nasretdinova R.N., Islamova R.M., Koifman O.I., Monakov Yu.B. Izv. Vyssh. Uchebn. Zaved., Khim. Khim. Tekhnol. 2006, 49, 24-28 (in Russ.).

20. Kabanov V.A., Zubov V.P., Semchikov Yu.D. KompleksnoRadikal'naya Polimerizatrsiya [Complex Radical Polymerization]. Moskva: Khimiya, 1987. 255 p.

21. Friesen A.K. In: Abstracts of X International Conference on Physical and Coordination Chemistry of Porphyrins and their Analogues. Ivanovo, ISUCT, 2009. p. 175.

Received 22.04.2011

Accepted 07.05.2011 